\title{
Ancient Chinese architecture in the future -An investigation with parametric modeling tools
}

\author{
Yuan $\mathrm{Li}^{1}$, Zhi $\mathrm{Li}^{2}$, Chang $\mathrm{Xu}^{3}$ \\ ${ }^{1}$ No.2 Department of Architectural Engineering, Planning and Design institute of Forest Products Industry, 100010 Beijing, China \\ ${ }^{2}$ College of Animation and Digital Arts, Communication University of China, 100024 Beijing, China \\ ${ }^{3}$ No.1 Department of Urban Planning, Planning and Design institute of Forest Products Industry, 100010 Beijing, China
}

\begin{abstract}
With the flexibility and modularity of the construction system, the ancient Chinese architecture was a configurative system until the modern time when it became figurative with nationalistic symbolism, and lost its flexibility to adapt in different functions. Through this study, the researchers try to exploit and release the powerful adaptation of this configurative system by using the method of parametric design. First of all, according to the modern parametric theory, the logic of the traditional structural system is found out by abandoning the feudal social hierarchical factors. And then, a 3D model of parametric structure with wide adaptability is established in Rhino by using its parametric design plug-in Grasshopper. Finally, on the basis of the modern parametric skin theory, two skin systems are attached to this new structure separately, in order to prove the feasibility of the new skin idea to this structure. Through the introduction of parametric modeling steps, this paper focuses on mining the modern adaptability of Chinese traditional architecture.
\end{abstract}

\section{Introduction}

\subsection{The ancient Chinese architecture and the configurative architecture system}

\subsubsection{The flexibility of construction system in Ancient Chinese architecture}

Ancient Chinese architecture has a wonderful construction system.

The structure of ancient buildings has flexibility to adapt to nearly all kinds of building types and in different natural environment of China. For example, the structural flexibility can also be found in Buddhist or Taoist temples, since they are usually located in mountainous areas. "Xuankong Si", a Buddhist and Taoist temple in Shanxi province was built on a precipitous cliff with the wood structure and mortise and tenon joints. The temple was suspended in the air without support from ground.

However, the wonderful flexibility has been limited by some factors.

Firstly, the application of the building system has been limited to rectangular forms as a result of Chinese cosmological schema of a square shaped earth in the ancient times. This culturally defined conceptual representation of the universe overshadowed the potentials of the flexibility nature of the structural system. Nevertheless, the flexibility and potential of the structural system show brilliantly in the Temple of Heaven where the circular structures were required to reflect the cosmological schema of heaven that is circular.
Secondly, it was limited by the traditional single use of material and the feudal social hierarchy, although the truss structure can meet the spatial needs of people. Yet the feudal social hierarchy is related to the modular system in the traditional Chinese structural system.

To sum up, the flexibility of construction system is the natural quality in ancient Chinese architecture, although there were some limiting factors.

\subsubsection{The modular structural system}

The traditional Chinese structural system is modular. The basic module determines all the sizes structural components so as to control the scale of the entire building. When the dimensions of the basic module change, so do other parts of a building. Because of these features, the structure system is a configurative system. For example, structural components in the Temple of Heaven are similar to those used in the rectangular palaces of the Forbidden City are used to form the circular structure with similar modular rules of construction.

\subsubsection{The traditional Chinese architecture should be a configurative architecture system.}

The delicate wood bracket system and graceful hyperbolic roof draw so much attention that the logic behind the appearance is ignored. Most of people, even architects, think of old building's essential characteristics in terms of these external features. Therefore, in modern time, ancient Chinese architecture is treated as a figurative system with nationalistic symbolism. 
However, because of the flexibility and modularity of the structural system, the traditional Chinese buildings have a lot of striking formal features as Aldo van Eyck points out that configurative architecture is figurative $e^{1 .}$

Therefore, the traditional Chinese architecture should be treated to be a configurative architecture system.

\subsection{The construction system and parametric design}

Since the traditional Chinese structural system is a rule based modular system, it can be seen as a parametric system with the basic modular unit as its main parameter. When the value of the parameter changes, all the parts change according to the rule. In the theory of parametric design, swarm intelligence is the property of a system whereby the collective behaviors of agents interacting locally with their environment cause coherent functional global patterns to emerge. In the case of a traditional Chinese building, the individual components can be seen as the agents whose behavior is determined by the construction rules, and the whole building can thus be seen as the global pattern of emergence.

\subsection{The aim of this study}

The intention of this study is to investigate the adaptability of a parametric model of a structure based on the traditional Chinese structural system in order to demonstrate that when the traditional Chinese architecture is treated as a configurative building system, it can better serve contemporary functions in more irregular sites, and result in new figurative images. In such a way, the configurative nature of the traditional Chinese architecture can be rediscovered, and the ancient tradition can be reconnected with the contemporary life to give the traditional architecture a new life. Then the parametric design tools can be used to explore the future Chinese architecture based on the logic of the traditional constructional system.

\subsection{The research status}

In recent years, many Chinese architects have used parametric methods to study traditional Chinese architecture. However, some of them were concerned with on the form of the bracket sets of the traditional Chinese architecture. One direction is to explore the automation of the generative process of the bracket sets as a figurative system representing the Chinese architectural tradition ${ }^{23}$. And other studies were interested in how to use parametric tools to recover the ancient buildings ${ }^{3}$. These studies may still miss the more fundamental aspect of the Chinese architectural tradition. Therefore, this study will concentrate on the configuration of the post and beam structure in its adaptive use.

\section{Process}

\subsection{Logic and rules}

According to studying the module and structure system, the logic of Chinese antique was found out. The unit of the structure system is a piece of truss, composed with two pillars supporting several lays of beams and roof curves by linking the points of beam heads. Two pieces of units, hyperboloid roof and the clearance between them compose a space. This is the logic of the ancient structure. Because of the logic, the structure can create a series of space which china people live with. The royal palaces were built by this structure, so were the dwellings. The temples of Buddhism, whatever large or small and imperial or folk, were built by the structure. The buildings, the corridors and the pavilions were built by the same structure. However, there is hierarchy in China whatever past or present. However, this is impossible that there is no difference between royal palaces and folk dwellings, temples and residential buildings. Strict hierarchy system controlled all of architecture. Ancient Chinese made a special module rules to control the scale of a building and the luxuriant degrees. According to it, the difference can exist.

To sum up, the dimension of every components and clearance between two units are controlled by a modular system. And how did the special module rules work? It was ruled that there are two kind of architecture - big type building system and small type building system. The big type system applied to the official and royal architecture, while the small type system applied to the folk and some subsidiary architecture, even of royal. And the most distinguish is whether there is Dougong, a system of brackets inserted between the top of a pillars and a crossbeam, which can let the eaves more profound. In the official building system, the basic module is the dimension of Douko, the smallest dimension of the mortise and tenon joint between beam and pillars. There are 10 basic module graded the architecture to 10 levels. The dimension of basic module is bigger, the class is higher, the ornament is more luxuriant. In the small type system, the basic one is the diameter of pillar. Every component of a building has the ratio of diameter. As a result, the dimension of pillar diameter and these radios control a building. Because of these module systems, the logic of Chinese ancient architecture can be studied by parameter methods.

\section{2 modeling}

A model has been build in Rhino by using plug-in Grasshopper to finish this study.

In the studying, I dislodge these factors what exist due to strict hierarchy system, yet reserving those original elements. And it should be gotten rid of the limit of materials. Consequently, these factors are reserved: the unit of the structure system, which is a piece of truss, composed with two pillars supporting several layers of beams and roof curves by linking the points of beam heads, the module system without those 10 levels. The radio will be reserved, too. It displays the relation of each component 
clearly.

\subsubsection{To build a structure}

The structure was built, by constructing the pillars, beams and roof keels. The first step is drawing a curve. It simulates the wavy terrain and different spatial needs.

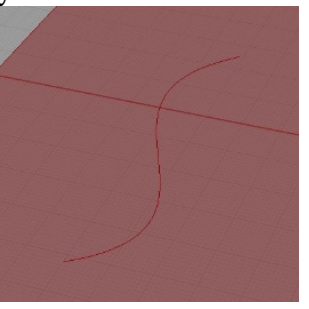

Fig. 1. The original curve (be made by author).

And then the curve was divided (Figure 2). One group of pillars would be built on these dividing points. There were another curve and two new points which were drew. The function of the controlling points and curve is to simulate some special influence factors to the building. Therefore, some relations would be set up between controlling factors and the building. It is known that the height and width can control the scale of a space, so that they can control a building. Therefore, it was set that the height of the pillars were controlled by the dimension between one point and theses dividing points, and the width would be controlled by the relations between another point and these points in the curve between old group of pillars and new group. It means that the height were not the same with every pillars and there would be a curve in $\mathrm{Z}$ direction, and so did between two group of pillars (Figure 3).

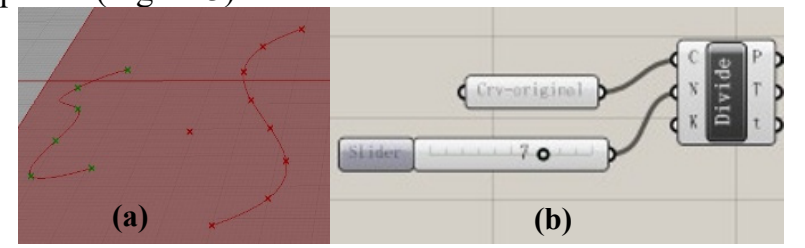

Fig. 2. To divide the curve (be made by author).

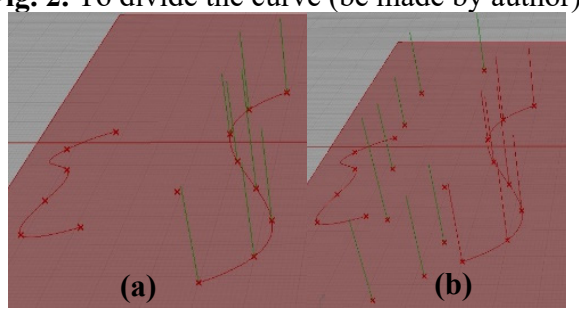

Fig. 3. (a). To build a group of pillars. (b). To build another group of pillars. (Be made by author)

The third step is to finish the last layer of the truss structure, the multilayer triangle beam frames. Like the Figure 4, a group of pieces of post-and-beam structure would be set up.

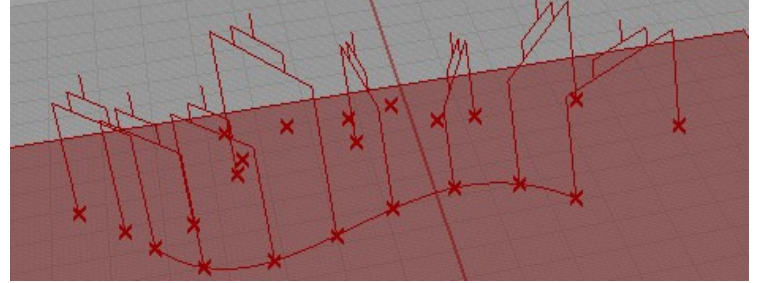

Fig. 4. The multilayer triangle beam frames (be made by author).

In addition, it is the forth step to connect these postand-beam structure pieces by setting the roof purlins in sequence (like Figure 5 and Figure 6).

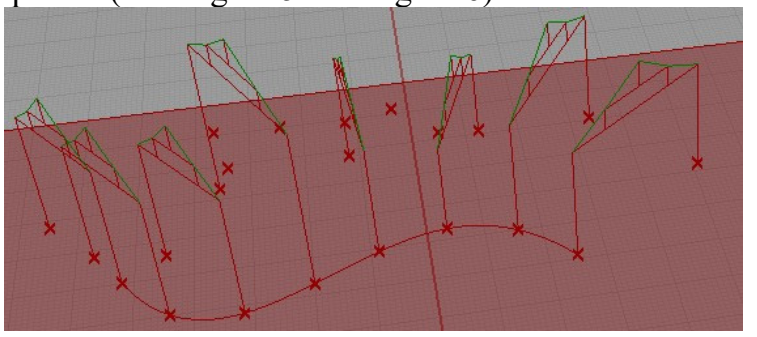

Fig. 5. To connect these post-and-beam structure pieces (be made by author).

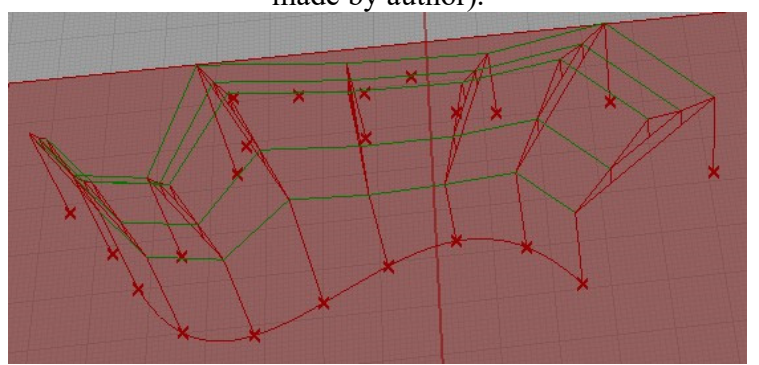

Fig. 6. The primary structure (be made by author).

By the end of this step, the primary structure was built (like Figure 6). roof.

The fifth step is connecting all the purlins to make the

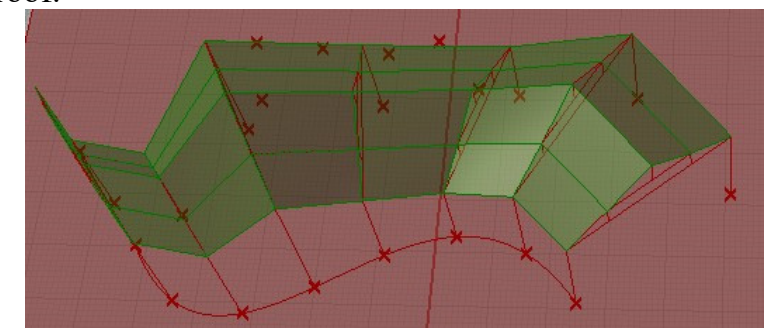

Fig. 7. To loft a roof (be made by author).

For protecting the wall, the cornices would be set up (Figure 8). It is the last step. The angle between cornices and the eave curves would be adjusted in order to adjust to some surrounding requirements. It was carried out by offsetting the eave curves, lofting the two curves and setting a slide bar to control the angle(like Figure 9 and Figure 10). 


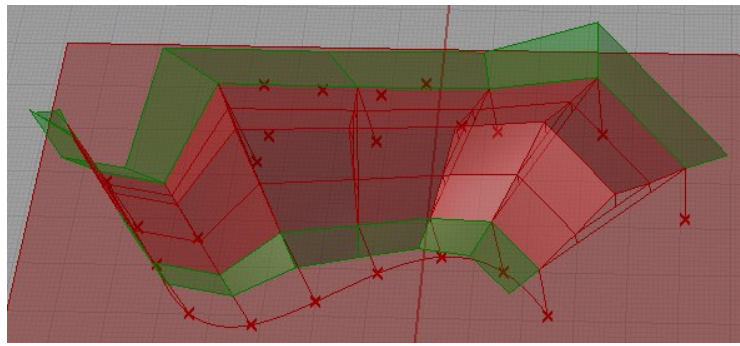

Fig. 8. To overhang eaves (be made by author).

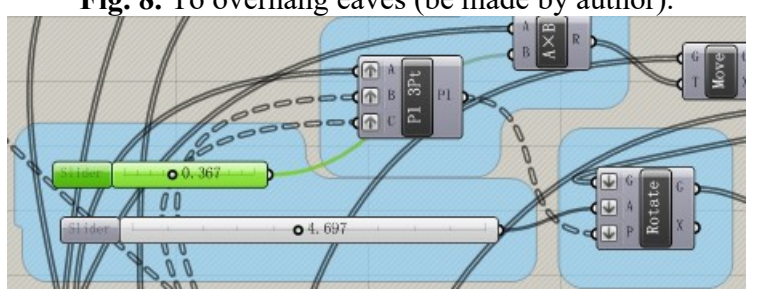

Fig. 9. The slide bars to control the angle (down bar) and the length (up bar). (Be made by author)

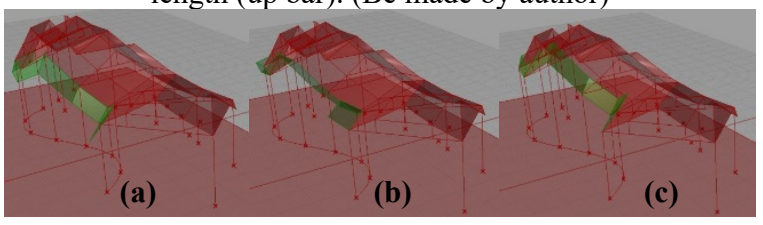

Fig. 10. The process of the eave's angle changing (be made by author).

\subsubsection{The vertical space was divided and created.}

To divide and create the vertical space. In other words, the floors were built. In one group of pillars, select some pillars, set one slideable point in one pillar and link these points to a floor curve (figure 11-a). In the other pillar group, by doing the same thing, another curve will be drawn (figure 11-b). Then lofting the two curves set up a floor (Figure 11-c). By controlling these slidable points, the height of the floors could be changed (figure 12-a). By using this method, multiple floors can be built basic on the different requirements. And the important thing is that the vertical space would be changeful and interesting. In ancient Chinese architecture, these parts of hangover outside floors were considered. In order to protect these walls and the floors, large cornices are the solution. The making method is similar with making the roof cornice with the slidable angle (Figure 13 and Figure 14).
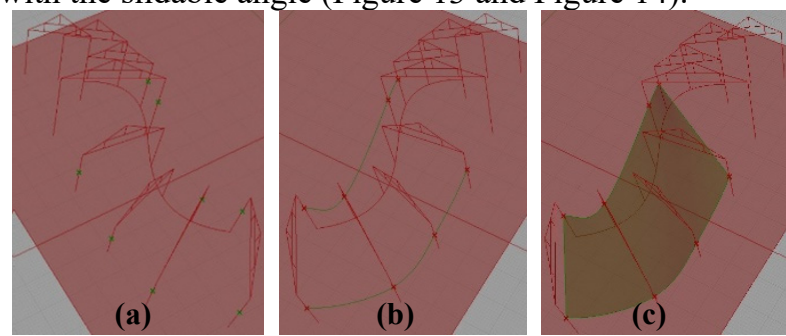

Fig. 11. The process of the first floor was built (be made by author).

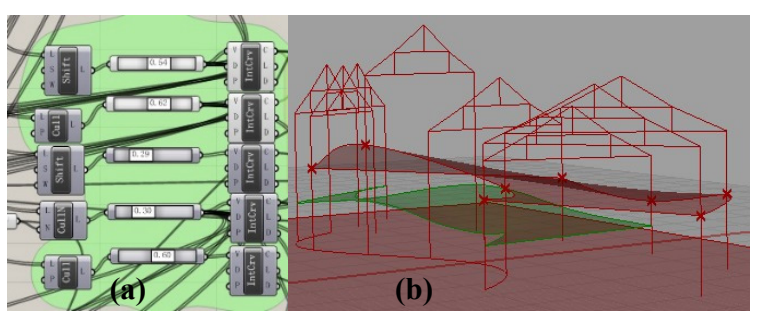

Fig. 12 (a). slide bars to build two floors in Grasshopper; (b). the second floor was built in Rhino. (Be made by author)

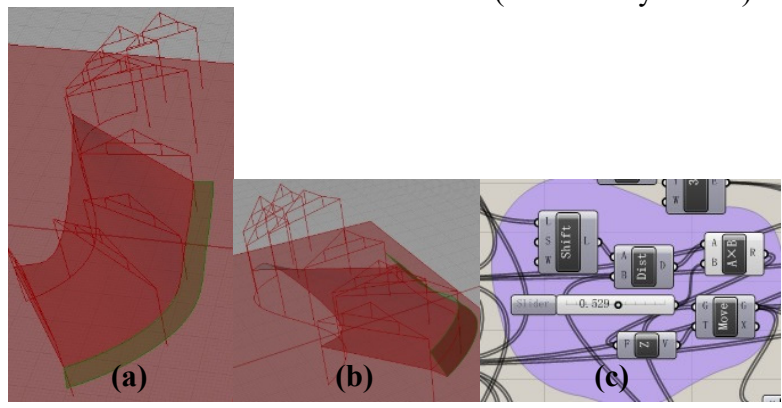

Fig. 13. (a)\&(b). the overhanging floor; (c). The slid bars in Grasshopper to control the eave's angle of overhanging floor (be made by author).

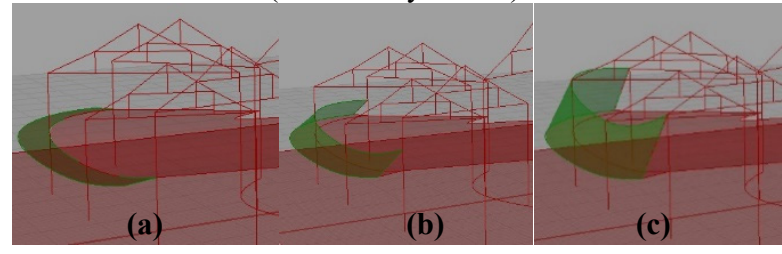

Fig. 14. The process of the eave's angle changing about the overhanging floor primary structure (be made by author).

At last, the structure modeling which is simplified is created.
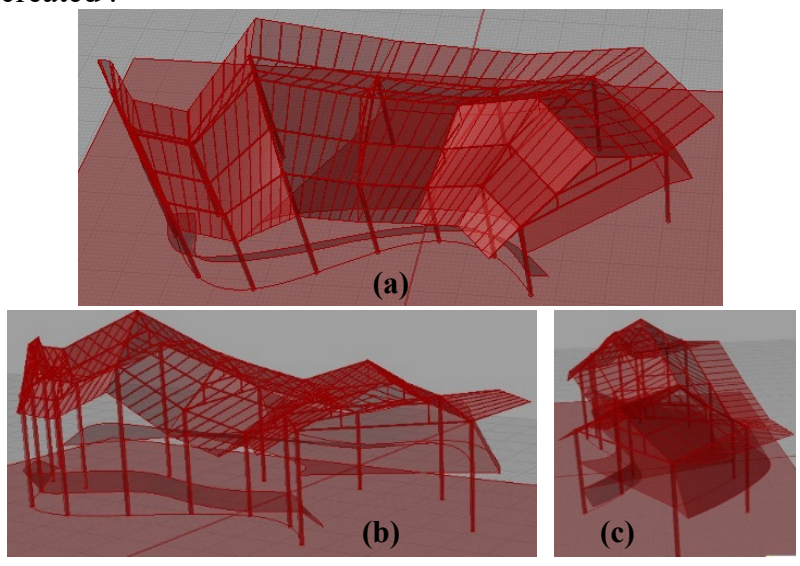

Fig. 15. The simplified structure modeling (be made by author).

\subsubsection{Building envelopes would be built.}

Building envelopes would be built. Because the truss structure system is the supporting system, the building skin is unconstrained, whatever in the form or in material. The current methods and skin theories are adaptable/ applicative.

According to the current theories of skin system, these steps would be followed:

1. To build a unit of skin. 
2. To made or choose a wall as a target wall.

3. To build the skin system by letting the unit of skin be attached to the target wall following some logic rules.

\subsubsection{To build the first skin system with "亞"}

Considering the cultural factors, “亞”(Ya), as one of the ancient Chinese words, is chosen to build the first skin system.

Firstly, the reason why "亞” was chosen is that the pattern of “亞”, as one of the traditional patterns in ancient China, was often used on the grid/window/door of ancient Chinese buildings. In this study, a attempt to apply the pattern of "亞" to the surface of architecture in a new way will show that Chinese tradition and traditional architecture can be revived in the contemporary era.

Secondly, a skin system of “亞” is built in Rhino by following the modeling steps:

1. Under the guidance of multi-dimensional mindset, the "亞" pattern is made into a three-dimensional unit, like Figure 16(a). In this attempt, the middle part of the "亞" three-dimensional unit is set to be raised, so that the unit will have multiple faces . By giving different attributes to different faces, the adaptability of skin system can be improved.

2. To make a target wall by connecting two curves, like Figure 16(b). The one curve is the original curve in the ground, and the other curve is made by linking apexes of columns. In this way, the target wall is simplified a curved surface, so that the wall thickness is $0 \mathrm{~mm}$.

3. The "亞" three-dimensional unit is attached to the target wall in order to build the skin system, like Figure 16(c).

Thirdly, through giving different attributes to different skin units, the external windows can be set in the architectural skin which is building envelopes. And there are two ways.

The one way is that: some "亞" units are defined as entities, while others are defined as void bodies which can be regarded as windows of buildings. Therefore, the light can enter into the building through the parts of skin attached by void units. Following different light requirements of architectural space and other factors, the suitable materials would be chosen or created to fit the requirements of light transmittance.

According to this logic, for a unit, we can choose some surfaces in a "亞" unit to be solid, while others to be virtual. Because the angle and area of each surface of "亞" unit can be set and changed by parameters, amount of light and incidence angle can be controlled according to the actual situation .

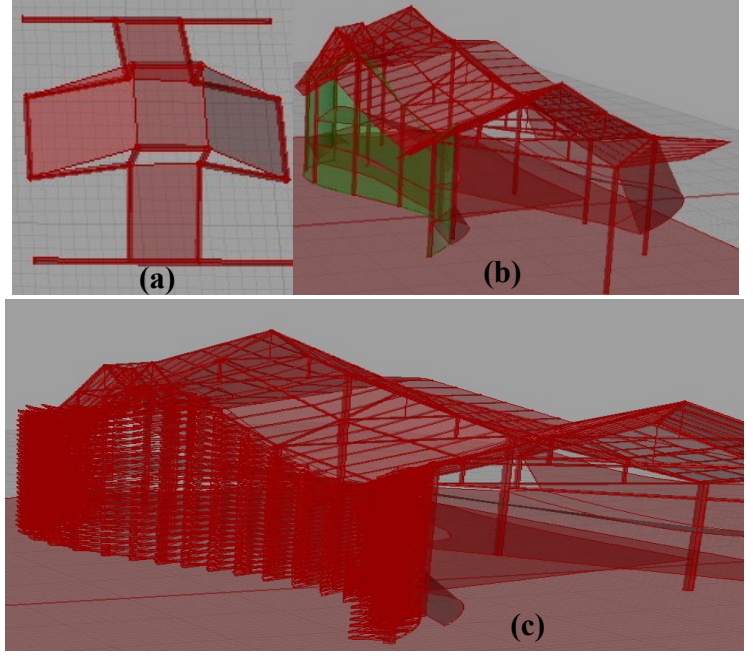

Fig. 16. To build one skin system (be made by author).

\subsubsection{To build the second skin system with light as the main factor.}

Another attempt is made to adapt the skin of this structural system. Without cultural factors, light is chosen to be the unique/main influencing factor. At first, to make a unit with a hole in the middle which the hole's area can be controlled according to the illumination of light, like Figure 17(a). And then, the unit is attached to the exterior wall, like Figure 17(b) and (c). This is the most common method of making skin method in contemporary times.

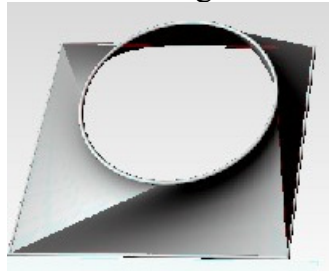

(a)
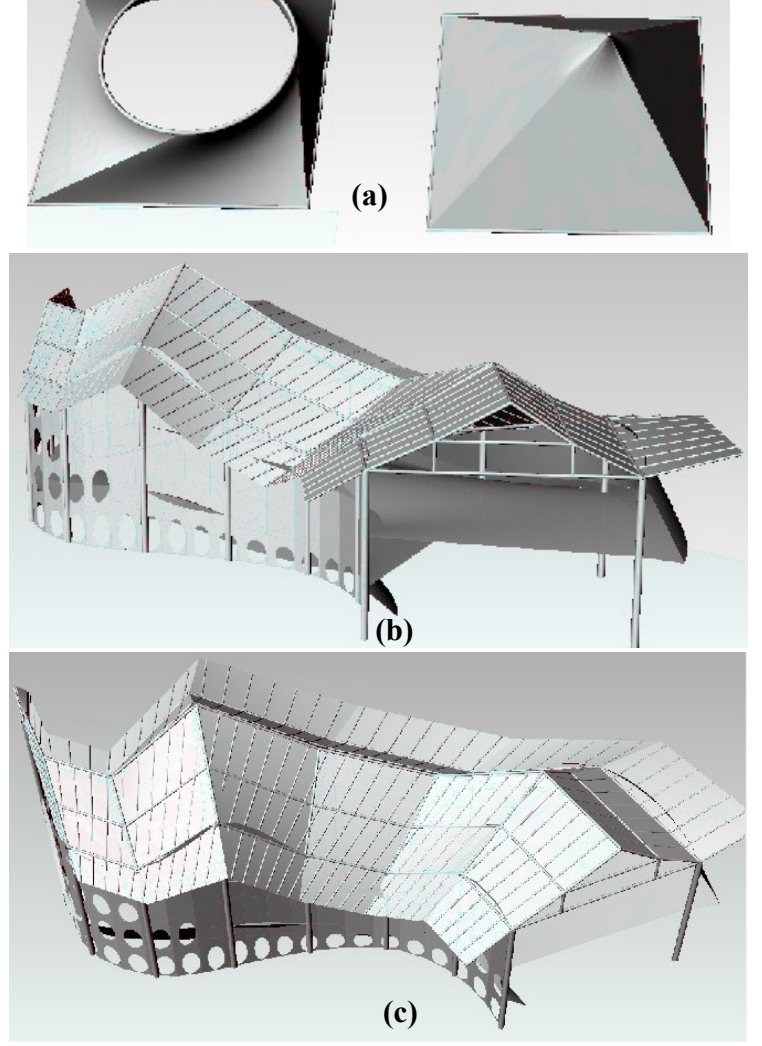

Fig. 17. To build the other skin system (be made by author).

Above that, it is viable that new methods of architectural skin design adapted to the truss structure 
system from ancient Chinese Architecture.

\subsection{Result}

In this study, the model was controlled by 3 parameters.

The first one is basic curve and the dividing numbers of this curve. The curve comes from the simulation of the site conditions. In a real project, the simulate cure could come from abstracting the site conditions, such some geography condition and so on. By changing the numbers in the curve, the number of truss pieces could be changed and the dimension between two pieces could be altered; by changing the trend of the curve, the trend of the building would be changed. And the rule which control the number is basic on the requirement of the materials and the load condition.

The second factor is the controlling curves and points. By moving the points and the curves, the height of each pillars and the depth of each room could be altered. Those two alterable factors were set to simulate the varied terrain and other effects which influence the building volume and spatial arrangement.

The third one is the slide bar to control the angle of the pitch to the eave. In old buildings, for protecting the roof and the wall from the rain and snow, the hangover eaves occupied. And the raked roof is good for dewatering naturally. As a result, with the structure supporting, the eaves were raked and hangover. The deeply hangover eaves are necessary. By offsetting the eave curve and lofting the two curves, the hangover eaves were built. And set two slide bars, one is to control the pitch to the eaves and the other is to control the hangover length. It is good to find the adaptable angel and length of the eaves, according to the local natural surrounding factors. For example, if the sunlight is one of the main influences to a building, the length and angle can alter following the changes of light.

However the model abandons the old ratio between each dimension of components. The old ratio rules related to the vertical and horizontal loads of building, because the ratio rules control the dimension of the pillars, beams and other structure components which made of wood to adopt to the vertical and horizontal loads of a building. Moreover the ratio rules came from the experiences. Consequently, when the material science and mechanical system are developed, the ratios will be no more adoptable, so the old ratios are given up. And the dimension of each component could be controlled by a new ratio system basic on new material and load situation. In another word, the method is continued that a ratio system control the dimensions. The only improvement is that a new ratio system will instead of the old one.

\section{Conclusion}

The ancient Chinese architecture is a configurative system. In the modern time, it is important to exploit and release the powerful adaptation of this configurative system.

The first key factor which must be reserved is the unit of the structure system, which is a piece of truss, composed with two pillars supporting several layers of beams and roof curves by linking the points of beam heads. By abstracting the specific condition of a program to a curve and the key influence to points, the controlling parameter could be found out. And these parameters will manage the permutation and combination of the unit structure pieces. Because of this, the form and spatial combination will be controlled by parameters. At the same time, the advantages can emerge.

The second key point is to continue the method that the dimensions are controlled by a ratio system. The improvement is that the new ratio system would instead of the old ratio system. These rates are the other group parameters.

I am greatly indebted to my supervisor, professor Feng Jin who is teaching in Lawrence Technological University, for his valuable instructions, suggestions and criticism on my paper in the academic studies as well as his careful guidance of the translation. In addition, I also owe a special debt of gratitude to professor Zhang Bo who once offered me valuable courses and advice during my study. Last but not least, my gratitude also extends to my family members, especially my mother and husband. Their encouragements and unwavering supports have sustained me through frustration and depression. Without their pushing me ahead, the completion of this paper would be impossible.

\section{REFERENCES}

1. A.van Eyck, Forum, 3, 81-93 (1962)

2. P. Ma, W. Zhao, J. Chongqing Univ. Sci. Technol.(Natural Sci. Edition), 11(6), 94-97(2009)

3. Z. Wang, J. Lu, B. Zheng, Sichuan Building Sci., 45(2), 78-82 (2019)

4. Y. Chen, J. Liangshan Univ., 4(1), 19-21(2002)

5. R. Wang, W. Sun, X. Zhang, J. Xi'an Univ. of Arch. \& Tech.(Natural Sci. Edition), 45(4), 479-486(2013) 